\title{
A Functionalised Macrobicycle Complex Available for Surface Immobilisation and Protein Grafting
}

\author{
Paul V. Bernhardt,, Jack M. Harrowfield, ${ }^{\ddagger}$ Yang Kim, ${ }^{\circ}$ Young Hoon Lee, ${ }^{\S}$ Yu Cheol Park,,${ }^{\sharp}$ and Sujandi \\ Department of Chemistry and Adanced haterials, Kosin Lhiversity, Busan 606-701, Korea. E-mail: wimakosinac.kr \\ 'Department of Chemistry, Lniversity of Queenstand, Brisbane 4072 , Australia \\ 'Laboratoire de Chimie Stupramoleculaire, LAR 7006 di CNRS, Institut de Science et dingénierie. Supramoleculaires, \\ Strasbotirg 67083, France. \\ sDepartment of Chemistry, Kythgpook National Chiversitw, Daegu 702-701, Korea \\ Received Januarv 2, 2007
}

\begin{abstract}
The conversion of both the racemic and resolved forms of the Co(III) complex of an hydroxymethyl-substituted tripodal hexamine to macrobicycles via reaction with formaldehyde and nitromethane (and subsequent reduction of the product) has been conducted. The prospect is that it will provide cage complexes in which the hydroxỵl substituent is sufficiently remote from the metal ion centre for its mucelophilicity to be largely unaffected. X-ray stnicture determinations have been used to characterise these new cage species as well as some complexes of the precursor hexamine and its mono-aminal. The electrochemistry and optical activity of the complexes have also been studied in detail.
\end{abstract}

Key Words : Macrocycle, Co(III), Cage, Hexamine, Electrochemistry

\section{Introduction}

The macrobicyclic cage hexaamine "sarcophagine" (3.6. 10.13.16.19-hexa-azabicyclo[6.6.6]icosane) and its substituted analogues (see $\mathbf{1}$ and $\mathbf{2}$ in Figure 1) are capable of complexing a variety of metal ions, rendering them not only inert to substitution but amongst other things. imposing upon them a chiral environment. ${ }^{1-3}$ The remarkable properties of these caged metal ions have possible applications in biology..$^{4-5}$ energy conversion ${ }^{10-1 / 2}$ and materials science. ${ }^{13.14}$ For this. it must be possible to covalently attach the cage to other (macro)molecules or surfaces. which then demands the presence of reactive functional groups suitable for such grafting. While the external amino groups of complexes such as $[\mathrm{Co}(1)]^{3-}$ or $[\mathrm{Co}(2)]^{3+}$ have been used successfully' as such groups in reductive alkylation reactions ${ }^{13-16}$ reactions at these sites are inhibited by their proximity to the cationic centres. This problem may be alleviated if the functional group that is to be employed as a linker is more remote from the metal than the amino groups of 1 or 2 . In this paper we introduce the new disubstituted cages 3 and 4 where a synthetically useful hydroxymethyl group replaces the inert methyl group of the simpler analogue 1.

Our approach insolves a combination of organic and transition metal template syntheses. ${ }^{17}$ Recently we have reported the hydroxymethyl substituted tripodal hexamine 5 isolated as its $\mathrm{Co}(\mathrm{III})$ complex $[\mathrm{Co}(\mathbf{5})]^{3+} .{ }^{\S}$ The ligand $\mathbf{5}$ may be viewed as a precursor to 3 and 4 in that upon complexation with $\mathrm{Co}^{111}$ it provides a triplet of facially coordinated primary amino groups that may be 'capped' with formaldehyde and a tribasic acid such as MeNO. 1.2.15.20 The nitro-substituted cage is then easily reduced to the amine derivative without loss of the metal ion. The ligands 3 and 4 thus possess a hydroxyl group remote from the metal ion

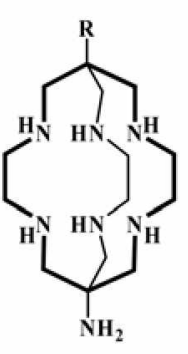

(1) $\mathrm{R}=\mathrm{CH}_{3}$
(2) $\mathrm{R}=\mathrm{NH}_{2}$
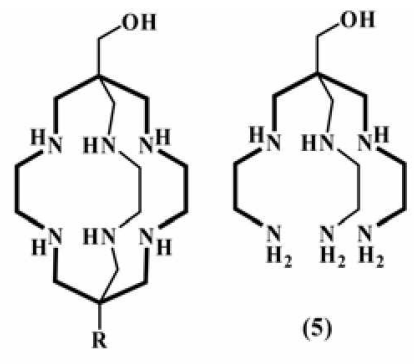

(5)
(4) $\mathrm{R}=\mathrm{NH}_{2}$

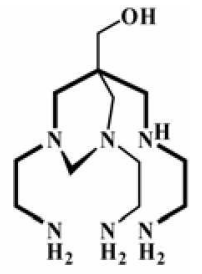

(6)
Figure 1. The hexalamine ligands discussed in this work.

that may be activated for nucleophilic substitution reactions through e.g. the formation of reactive sulfonyl esters. The present work is an extension of our broader studies on the synthesis and properties of ligands functionalised with the sy'nthetically useful hydroxymethyl group and we include herein description of some of the basic coordination chemistry of the new cage complexes derived from $[\mathrm{Co}(5)]^{3-}$. The enantiomers of this complex. described herein. are precursors to the chiral cages $[\mathrm{CO}(3)]^{3+}$ and $[\mathrm{Co}(4)]^{3+}$. We also report the isolation of an unusual byproduct from the sy'nthesis of 5. namely the aminal 6 . which is incapable of coordinating as a hexadentate but which can bind as a quadridentate.

\section{Experimental Section}

Materials and equipment. Pentaery thritol tribromide was purchased from Tokyo Kasei (Japan) and other chemicals from Aldrich and used as received. The synthesis of (5) and purification by isolation of its $\mathrm{Co}^{\mathrm{II}}$ complex. $[\mathrm{Co}(5)] \mathrm{Cl}_{2} \cdot \mathrm{H}_{2} \mathrm{O}$ has been described elsewhere ${ }^{18}$ Ion exchange chromatography was conducted in glass colununs under gravity flow 
using either SP-Sephadex C.25 $\left(\mathrm{Na}^{+}\right.$forml) or Dowex $50 \mathrm{~W} \times 2\left(\mathrm{H}^{-}\right.$form $)$ion-exchange resins.

Cyclic voltammetry employed a BAS $100 \mathrm{~B} / \mathrm{W}$ potentiostat attached to a PAR Model 303 dropping mercury working electrode. a $\mathrm{Pt}$ counter and $\mathrm{Ag} / \mathrm{AgCl}$ reference electrode. The supporting electrolyte was $0.1 \mathrm{M} \mathrm{NaNO}_{3}$ and all solutions were purged with $\mathrm{N}$ : prior to measurement. IR spectra were recorded with a JASCO FT-IR $\mathbf{5 3 0 0}$ with compounds dispersed as $\mathrm{KBr}$ discs. UV/vis absorption spectra were measured on a SCINCO S-2100 diode-array spectrophotometer and circular dichroism (CD) spectra on a Jasco 715 spectrometer. All solution measurements were made at $25 \pm$ $1{ }^{\circ} \mathrm{C}$. Elemental analyses were carried out with a Chemtronics TEA-3000 instrument.

\section{Syntheses}

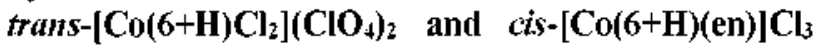
$\left(\mathrm{ClO}_{4}\right) \cdot \frac{1}{2} \mathrm{H}_{2} \mathrm{O}$ : Pentaery thritol tribromide $(5.0 \mathrm{~g} .15 .4 \mathrm{nmol})$ was gradually added to ethane-1.2-diamine (en) (18.0 g. 300 mmol) and the mixture heated at $120^{\circ} \mathrm{C}$ for $72 \mathrm{~h}$. The bulk of the excess diamine was distilled out under reduced pressure before adding $\mathrm{NaOH}(1.9 \mathrm{~g}$ in $200 \mathrm{~mL}$ methanol. 48 mmol) to the yellow oil which was stirred for $0.5 \mathrm{~h}$. The solvent and diamine were removed by distillation under reduced pressure. The yellow viscous residue was dissolved in methanol $(100 \mathrm{~mL})$, then $\mathrm{CoCl}_{2} \cdot 6 \mathrm{H}_{2} \mathrm{O}(3.8 \mathrm{~g}$ in $400 \mathrm{~mL}$ methanol. $16 \mathrm{mmol}$ ) and acetic acid $(10 \mathrm{~mL})$ were added and the mixture was aerated for $5 \mathrm{~h} . \mathrm{HCl}\left(2 \mathrm{~mol} \mathrm{~L}^{-1} .20 \mathrm{~mL}\right)$ was added and the solution evaporated to dryness under reduced pressure. The residue was dissolved in water $(500 \mathrm{~mL})$, then absorbed on a chromatography column containing Dowex $50 \mathrm{~W} \times 2$ ion-exchange resin $\left(\mathrm{H}^{-}\right.$form, $\left.7 \mathrm{~cm} \times 120 \mathrm{~cm}\right)$. The column was washed with water $(500 \mathrm{~mL})$ and eluted with $\mathrm{HCl}\left(2 \mathrm{~mol} \mathrm{~L}{ }^{-1}\right)$ to give five bands. The first band was unreacted $\mathrm{Co}_{a q}{ }^{3+}$ (pink). the second $c i s-\left[\mathrm{Co}(\mathrm{en})_{2}\left(\mathrm{OH}_{2}\right) \mathrm{Cl}\right]^{3+}$ (purple), the third trans-[Co(6) $\left.\mathrm{Cl}_{2}\right]^{\hat{2}^{-}}$(green), the fourth cis$[\mathrm{Co}(6)(\mathrm{en})]^{4+}$ (red) and the fifth $[\mathrm{Co}(5)]^{3+}$ (yellow) as the major product. which has been characterized ${ }^{18}$ previously. The third (F3) and the fourth (F4) bands were evaporated to dryness under reduced pressure to give their chloride salts. Yields (crude): F3 1.1 g. F4 $0.25 \mathrm{~g}$. Slow evaporation of an aqueous solution of each compound to which $\mathrm{NaClO}_{4}$ had been added provided green (F3) and red crystals $(\mathrm{F} 4)$ suitable for the structure determination. And. F3: Calc. for $\mathrm{C}_{13} \mathrm{H}_{29} \mathrm{Cl}_{4} \mathrm{CoN}_{6} \mathrm{O}_{0}: \mathrm{C}, 23.94: \mathrm{H}, 4.85: \mathrm{N}$. 13.96. Found: $\mathrm{C}$. 23.9: H. 5.1: N. $14.1 \%$. Visible spectrum (in water), $\lambda_{\text {max }}$ (nin) $\left(\log \varepsilon_{\max }\left(\mathrm{M}^{-1} \mathrm{~cm}^{-1}\right)\right) 650(1.81), 467$ (1.53. sh). F4: Calc. for $\mathrm{C}_{14} \mathrm{H}_{46} \mathrm{Cl}_{4} \mathrm{CoN}_{5} \mathrm{O}_{5} ; \mathrm{C}, 27.60 ; \mathrm{H}, 6.62 ; \mathrm{N}, 18.39$. Found: C. 27.5; H. 6.3: N. 18.4\%. Visible spectrum (in water). $\hat{\lambda}_{\text {max }}(\mathrm{nm})\left(\log \varepsilon_{\max }\left(\mathrm{M}^{-1} \mathrm{~cm}^{-1}\right)\right) 622(1.13), 490(1.82)$, $345(2.10$, sh).

$\Lambda$ and $\Delta-[\mathbf{C o}(5)]^{3+}$ (chromatographic resolution): Racemic $[\mathrm{Co}(5)] \mathrm{Cl}_{3} \cdot \mathrm{H}_{2} \mathrm{O}(2.5 \mathrm{~g})$ was dissolved in water $(500 \mathrm{~mL})$ and absorbed onto a colunn of SP-Sephadex C-25 $\left(\mathrm{Na}^{+}\right.$ form. $7 \mathrm{~cm} \times 120 \mathrm{~cm})$ then eluted with $\mathrm{Na}_{2}\left[\mathrm{Sb}_{2}(d \text {-tart })_{2}\right]$ $\left(0.15 \mathrm{~mol} \mathrm{~L}{ }^{3}\right)$ to give two yellow bands. The first band eluted was found to be L-[Co(5) $]^{\text {s- }}$ (see crystallography below). Each eluate was charged onto a Dowex $50 \mathrm{~W} \times 2$ colunm to remove the chiral anion. After washing with water $(200 \mathrm{~mL})$ and dilute $\mathrm{HCl}\left(0.5 \mathrm{~mol} \mathrm{~L}^{-1}\right)$ the optically pure cation eluted with $\mathrm{HCl}\left(3 \mathrm{~mol} \mathrm{~L}^{-1}\right)$. This was evaporated to dryness under reduced pressure. The yield was quantitative. Each fraction was redissolved in a minimum volume of water then excess $\mathrm{NaClO}_{4}$ was added to each solution. Vapour diffusion of ethanol into each solution produced orange crystals of the mixed chloride-perchlorate salt suitable for X-ray work. Crystals from the first eluted fraction were used for cry stallography. Anal. Calc. for $\mathrm{C}_{11} \mathrm{H}_{310} \mathrm{Cl}_{3} \mathrm{CoN}_{6} \mathrm{O}_{5}: \mathrm{C}, 26.87$. H. 6.15: N. 17.09. Found: C. 26.6: H. 6.1: N. 17.2\%. Visible spectrum, $\lambda_{\text {max }}(\mathrm{rm})\left(\log \varepsilon_{\text {max }}\left(\mathrm{M}^{-1} \mathrm{~cm}^{-1}\right)\right) 467(1.99), 341$ (1.93). CD spectra of $\Lambda-[\mathrm{Co}(5)]^{3-}$. $\lambda_{\text {mnumax }}(\mathrm{nm})\left(\Delta \varepsilon\left(\mathrm{M}^{-1}\right.\right.$ $\left.\mathrm{cm}^{-1}\right)$ ) $488(+0.42) .440(-0.60) .340(+0.070)$; and $\Delta$ $[\mathrm{Co}(5)]^{2-} . \lambda_{\text {mnumax }}(\mathrm{nm})\left(\Delta \varepsilon\left(\mathrm{M}^{-1} \mathrm{~cm}^{-1}\right)\right) 488(-0.42), 440$ $(+0.60) .340(-0.070)$.

$[\mathrm{Co}(3)] \mathrm{Cl}_{3} \cdot 1.5 \mathrm{H}_{2} \mathrm{O}$ : Racemic $[\mathrm{Co}(5)] \mathrm{Cl}_{3} \cdot \mathrm{H}_{2} \mathrm{O}(\mathrm{l} .0 \mathrm{~g})$ was dissolved in water $(100 \mathrm{~mL})$ and formaldehyde $(6.3 \mathrm{~g})$. nitromethane $(1.3 \mathrm{~g})$, and $\mathrm{Na}_{2} \mathrm{CO}_{3}(1.0 \mathrm{~g})$ were added. After standing at room temperature for $3 \mathrm{~d}$ the reaction was quenched by addition of $\mathrm{HCl}\left(2 \mathrm{~mol} \mathrm{~L}{ }^{-1} .30 \mathrm{~mL}\right)$ and heated at $60^{\circ} \mathrm{C}$ for $2 \mathrm{~h}$. The mixture was diluted to $\mathrm{l} \mathrm{L}$ and absorbed onto a colunn of SP-Sephadex C-25 $\left(\mathrm{Na}^{-}\right.$form. $7 \mathrm{~cm} \times 120$ $\mathrm{cm})$. washed with water $(200 \mathrm{~mL})$ and eluted with sodium citrate $\left(0.15 \mathrm{~mol} \mathrm{~L}^{-1}\right)$. An orange fraction was collected. applied onto a Dowex $50 \mathrm{~W} \times 2$ column and eluted with $\mathrm{HCl}$ $\left(3 \mathrm{~mol} \mathrm{~L}{ }^{-1}\right)$ after prior washing with water $(100 \mathrm{~mL}$ ) and $\mathrm{HCl}\left(0.5 \mathrm{~mol} \mathrm{~L}^{-1} .500 \mathrm{~mL}\right)$, respectively, then evaporated to dryness under reduced pressure. The compound was dissolved in a minium amount of water and vapour diffusion of ethanol applied to produce the crystals suitable for the X-ray work. (Yield. 1.2 g). Anal. Calc. for $\mathrm{C}_{15} \mathrm{H}_{36} \mathrm{Cl}_{3} \mathrm{CoN}_{7} \mathrm{O}_{45}: \mathrm{C}$, 32.65: H. 6.58: N. 17.77. Found: C. $32.5:$ H. $6.7:$ N. $18.0 \%$. Visible spectnum. $\lambda_{\text {max }}(\mathrm{nm})\left(\log \varepsilon_{\text {nax }}\left(\mathrm{M}^{-1} \mathrm{~cm}^{-1}\right)\right) 474(2.08)$, 342 (2.00). IR spectrum (KBr disc) $1555.1343 \mathrm{~cm}^{-1}\left(\mathrm{NO}_{2}\right)$.

$\Delta$ - and $\Lambda-[\mathrm{Co}(3)] \mathrm{Cl}_{2}\left(\mathrm{PF}_{6}\right): \Delta$ and $\Lambda \cdot[\mathrm{Co}(3)]^{3+}$ were each obtained directly via the same synthesis for the racemate (previous synthesis) but using either optically pure $\Delta$ - or $\Lambda$ $[\mathrm{Co}(5)] \mathrm{Cl}_{2}\left(\mathrm{ClO}_{4}\right)(0.5 \mathrm{~g}$. respectively) as the precursor. Following chromatography, as described above. addition of $\mathrm{NH}_{4} \mathrm{PF}_{6}$ to a concentrated aqueous solution of the chloride salt provided orange crystals suitable for a structure determination. (Yield. $0.57 \mathrm{~g}$ for $\Delta$-isomer and $0.56 \mathrm{~g}$ for $\Lambda$ isomer). Anal. Calc. for $\mathrm{C}_{13} \mathrm{H}_{33} \mathrm{Cl}_{2} \mathrm{CoF}_{6} \mathrm{~N}_{7} \mathrm{O}_{3} \mathrm{P}: \mathrm{C}, 28.40 ; \mathrm{H}$, 5.24 , N. 15.46 . Found $\mathrm{C} .28 .2$ : H, $5.3 ; \mathrm{N}, 15.6 \%$. CD spectra of $\Lambda-[\mathrm{Co}(3)]^{3-}, \lambda_{\text {mintmax }}(\mathrm{nm})\left(\Delta \varepsilon\left(\mathrm{M}^{-1} \mathrm{~cm}^{-1}\right)\right) 473(-2.14)$. $343(-0.18)$; and $\Delta-[\mathrm{Co}(3)]^{3+}$. $\lambda_{\text {mintmax }}(\mathrm{nm})\left(\Delta \varepsilon\left(\mathrm{M}^{-1} \mathrm{~cm}^{-1}\right)\right)$ $473(+2.14), 343(+0.18)$

$[\mathrm{Co}(4+\mathrm{H})]\left(\mathrm{S}_{2} \mathrm{O}_{6}\right)_{2}:$ Racemic $[\mathrm{Co}(3)] \mathrm{Cl}_{3} \cdot 1.5 \mathrm{H}_{2} \mathrm{O}(2.0 \mathrm{~g})$ was dissolved in water $(100 \mathrm{~mL})$ and $\mathrm{Zn}$ powder $(5.0 \mathrm{~g})$ was added. $\mathrm{HCl}\left(3 \mathrm{~mol} \mathrm{~L}^{-1}, 200 \mathrm{~mL}\right)$ was added dropwise over $\mathrm{l}$ $\mathrm{h}$ while the reaction mixture was kept under a nitrogen atmosphere. The reaction mixture was monitored periodically by taking small aliquots and passing them over a small SP-Sephadex column with sodium citrate $\left(0.1 \mathrm{~mol} \mathrm{~L}^{-1}\right)$ as eluent until the only one band was seen. The suspension was filtered to remove unreacted $\mathrm{Zn}$ powder and the filtrate 
reoxidised by addition of $\mathrm{H}_{2} \mathrm{O}_{2}(30 \% .5 \mathrm{~mL})$ and heating at $60^{\circ} \mathrm{C}$ for $\mathrm{l} \mathrm{h}$. The yellowish orange solution was diluted to $\mathrm{l}$ $\mathrm{L}$ with water and absorbed onto a Dowex $50 \mathrm{~W} \times 2$ column. then eluted with $\mathrm{HCl}\left(3 \mathrm{~mol} \mathrm{~L}^{-1}\right)$ after prior washing with water $(200 \mathrm{~mL})$ and $\mathrm{HCl}\left(0.5 \mathrm{~mol} \mathrm{~L}^{-1}\right)$. Trace amounts of pink $\mathrm{Co}_{2 q}{ }^{3+}$ eluted first well ahead of the dominant orange fraction of the desired product. The eluate was evaporated to dryness under reduced pressure and redissolved in a minimum amount of water. Ethanol $(300 \mathrm{~mL})$ was added to give a yellow precipitate. which was filtered and washed with ethanol. then dried under vacuum. The yield was almost quantitative $(1.9 \mathrm{~g})$. The chloride salt was dissolved in a minimum amount of water and lithium dithionate was added. Slow evaporation at room temperature afforded crystals of $[\mathrm{Co}(4+\mathrm{H})]\left(\mathrm{S}_{2} \mathrm{O}_{6}\right)_{2}$ but these were found to be twinned and unsuitable for X-ray work. Anat. Calc. for $\mathrm{C}_{15} \mathrm{H}_{36} \mathrm{CoN}_{7} \mathrm{O}_{13} \mathrm{~S}_{4}:$ C, 25.39; H. 5.11: N, 13.82. Found: $\mathrm{C}$. 25.2: H. 5.1: N. $13.7 \%$. ${ }^{13} \mathrm{C}$ NMR: d (ppm) 48.96. 51.50 . 55.11. 55.16. 56.48.57.79 and 63.10. Visible spectrum. $\lambda_{\text {max }}$ (nim) $\left(\log \varepsilon_{\max }\left(\mathrm{M}^{-1} \mathrm{~cm}^{-1}\right)\right) 473(2.10), 342$ (2.04). IR bands characteristic of the $\mathrm{NO}$ : group of $[\mathrm{Co}(3)]^{3-}$ disappeared whereas a new broad absorption near $3250 \mathrm{~cm}^{-1}$. characteristic of $\mathrm{NH}_{3}{ }^{-}$, appeared.

$\Delta$ - and $\Lambda-[\mathbf{C o}(4+H)]\left(S_{2} O_{6}\right)_{2}:$ The same preparative method leading to racemic $[\mathrm{Co}(4)]^{3+}$ was applied using optically pure $\Delta$ - or $\Lambda-[\operatorname{Co}(3)]^{3-}$ as the precursor. Addition of lithium dithionate to a concentrated solution of the chloride salt provided orange crystals. the yield was essentially quantitative. CD spectra of $\Lambda-[\mathrm{Co}(\mathbf{4}+\mathrm{H})]^{4-}, \lambda_{\text {mun } \max }(\mathrm{Im})\left(\Delta \varepsilon\left(\mathrm{M}^{-1}\right.\right.$ $\left.\left.\mathrm{cm}^{-1}\right)\right) 467(-2.37), 362(-0.13)$ : and $\Delta-[\mathrm{Co}(++\mathrm{H})]^{4-}, \hat{\mu}_{\text {mun }}$ :лаx (nim) $\left(\Delta \varepsilon\left(\mathrm{M}^{-1} \mathrm{~cm}^{-1}\right)\right) 467(+2.37), 362(+0.13)$.

Crystallography. Intensity data at $293 \mathrm{~K}$ were collected on an Enraf-Nonius CAD4 four-circle diffractometer using graphite monochromated Mo-K $\alpha$ radiation $(10.71073 \AA$ ) in the $\omega-2 \theta$ scan mode. Lattice dimensions were deternmined by a least squares fit of the setting parameters of 25 independent reflections. Data reduction and empirical absorption corrections ( $\psi$-scans) were performed with the WINGX package. ${ }^{2]}$ Structures were solved by heavy-atom methods with SHELXS and refined by full matrix least squares analysis with SHELXL97. All non-H atoms were refined with anisotropic thermal parameters. and $\mathrm{H}$-atoms were constrained at estimated positions. Crystal and refinement data are summarised in Table 1. The atomic nomenclature is defined in Figures 2-5 drawn with ORTEP3 ${ }^{23}$ CCDC 630750 to 630754 contain the supplementary crystallographic data for this paper in CIF format. These data can be obtained free of charge at www.ccdc.cam.ac.uk/conts/retrieving.html [or from the Cambridge Crystallographic Data Centre. 12 Union Road. Cambridge CB2 lEZ. UK: Fax: (internat.) + 44-1223/336033: E-mail: depositaccdc.cam.ac.uk].

\section{Results and Discussion}

Ligand Synthesis and Isolation of an Unusual Byproduct. We have recently reported the synthesis of the functionalised tripodal ligand $\mathbf{5}$ as is $\mathrm{Co}^{\mathrm{III}}$ complex. along with its $\mathrm{N}_{3} \mathrm{~S}_{3}$ analogue. ${ }^{18}$ Although the yield of the target hexaamine 5 is good. other products are formed. as shown here. The purification of polyamines is a process commonly rendered difficult by their involatility and resistance to crystallisation. A solution to this problem is to separate the various polyamine reaction products as either their $\mathrm{Co}^{\mathrm{III}}$ or $\mathrm{Cu}^{\mathrm{II}}$ complexes. The former approach is preferred when characterisation is the aim through the use of NMR techniques while the latter is more convenient when isolation of the purified metal free ligand is the target: $\mathrm{Cu}^{\mathrm{II}}$ complexes being labile and easily demetallated through reduction or precipitation

Table 1. Crystal Data

\begin{tabular}{|c|c|c|c|c|c|}
\hline & $\begin{array}{l}\text { cis-[Co(6+H)(en })] \mathrm{Cl}_{\xi-} \\
\left(\mathrm{ClO}_{4}\right), 1 / 2 \mathrm{H}_{-} \mathrm{O}\end{array}$ & $\begin{array}{l}\left.\text { truns-[Co }(6+\mathrm{H}) \mathrm{Cl}]_{2}\right]- \\
\left(\mathrm{ClO}_{4}\right)_{2}\end{array}$ & $\Lambda-[\mathrm{Co}(5)]\left(\mathrm{ClO}_{4}\right) \mathrm{Cl}_{2}$ & {$[\mathrm{Co}(3)] \mathrm{Cl}_{3} \cdot 1 / 2 \mathrm{H}_{2} \mathrm{O}$} & $\Lambda-[\mathrm{Co}(3)]\left(\mathrm{PF}_{5}\right) \mathrm{Cl}_{2}$ \\
\hline formula & $\mathrm{C}_{14} \mathrm{H}_{40} \mathrm{Cl}_{4} \mathrm{CON}_{8} \mathrm{O}_{3} \leqslant$ & $\mathrm{C}_{12} \mathrm{H}_{24} \mathrm{Cl}_{4} \mathrm{CoN}_{6} \mathrm{O}_{4}$ & $\mathrm{C}_{11} \mathrm{H}_{3,1} \mathrm{Cl}_{3} \mathrm{CoN}_{5} \mathrm{O}_{4}$ & $\mathrm{C}_{15} \mathrm{H}_{3 \times} \mathrm{Cl}_{3} \mathrm{CON} \div \mathrm{O}_{4}$ & $\mathrm{C}_{13} \mathrm{H}_{3} \mathrm{Cl}_{2} \mathrm{CoF} \mathrm{N}_{4} \mathrm{O}_{3} \mathrm{P}$ \\
\hline $\mathrm{fw}$ & 609.27 & 602.14 & 491.69 & 551.79 & 634.28 \\
\hline space group & $P \overline{1}(\mathrm{No} 0.2)$ & $P 2{ }_{l} / c(\mathrm{No}, 14)$ & $P 2{ }_{1} 2_{1}($ No. 19$)$ & Pnaa (No. 56) & $P 2_{1} 2_{1} 2_{1}($ No. 19$)$ \\
\hline$a, \AA$ & $9.945(2)$ & $13.196(2)$ & $9.3205(8)$ & $15.544(1)$ & $9.656(2)$ \\
\hline$b, \AA$ & $16.770(2)$ & $9.0856(6)$ & $13.6762(9)$ & $16.688(7)$ & $14.679(1)$ \\
\hline$c, \AA$ & $8.463(3)$ & $19.618(2)$ & $15.335(2)$ & $17.983(2)$ & $16.817(3)$ \\
\hline$\alpha$, & $85.87(1)$ & & & & \\
\hline$\beta, \infty$ & $75.81(2)$ & $102.87(2)$ & & & \\
\hline$\gamma{ }^{\circ}$ & $78.71(1)$ & & & & \\
\hline$r A^{3}$ & $1341.5(6)$ & $2293.0(4)$ & $1954.7(3)$ & $4665(2)$ & $2383.6(7)$ \\
\hline$Z$ & 2 & 4 & 4 & 8 & 4 \\
\hline $\mathrm{T}, \mathrm{K}$ & 293 & 293 & 293 & 293 & 293 \\
\hline$\lambda, \AA$ & 0.71073 & 0.71073 & 0.71073 & 0.71073 & 0.71073 \\
\hline !l, $\mathrm{cm}^{-1}$ & 10.80 & 12.71 & 13.24 & 11.19 & 10.93 \\
\hline$\rho_{c \sigma l l}, \mathrm{~g} \mathrm{cmn}^{-3}$ & 1.508 & 1.744 & 1.671 & 1.571 & 1.767 \\
\hline$R\left(F_{0}\right)^{b}$ & 0.0610 & 0.038 & 0.023 & 0.033 & 0.076 \\
\hline$w R_{\Delta}$ (all data) & 0.1959 & 0.108 & 0.060 & 0.097 & 0.241 \\
\hline
\end{tabular}

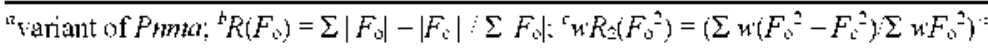




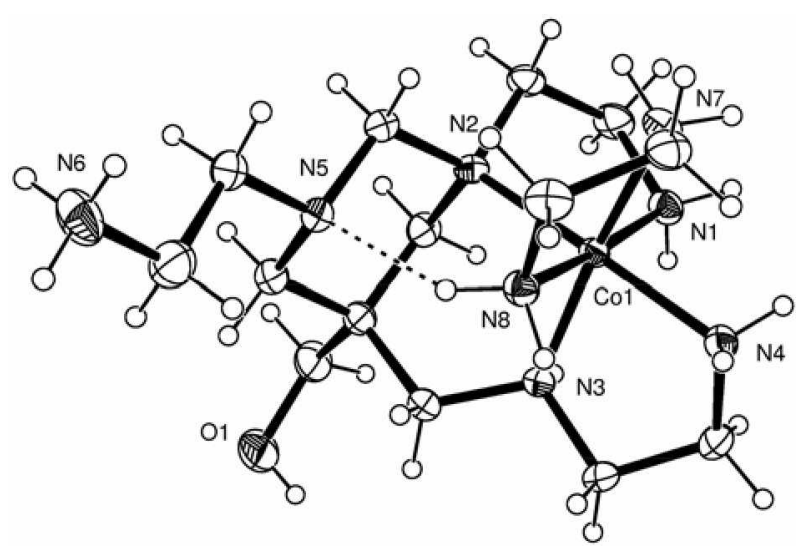

Figure 2. ORTEP view of the cis-[Co(6)(en) $]^{+-}$cation $(30 \%$ ellipsoids). Selected bond lengths $(A)$ : Co( 1$)-\mathrm{N}(1) 1.971(4)$, Co( 1 )$\mathrm{N}(2) 2.055(4), \mathrm{Co}(1)-\mathrm{N}(3)$ 1.974(4), Co(1)-N(4) 1.954(4), Co(1)N(7) $1.985(4)$ Co(1)-N(8) 1.966(4). The intramolecular H-bond $\left(\mathrm{N}(8)-\mathrm{H} \cdots \mathrm{N}(5) 2.08 \AA, 144.7^{\circ}\right)$ is also shown.

with sulfide. Interestingly. where $\mathrm{Cu}^{\text {II }}$ complexation has been performed in oxygenated $\mathrm{MeOH}$, this has sometimes led to the unanticipated formation of aminal (methylene-diamine) derivatives of the polyamines. ${ }^{2+}$

Here. we have found a similar instance of this type of chemistry through the identification of compound 6 where formaldehyde has bridged a pair of secondary amines. Given that no formaldehyde was present during the initial organic chemistry. we must conclude that the source of formaldehy'de was a $\mathrm{Co}^{\mathrm{ill}}$-mediated oxidation of $\mathrm{MeOH}$ to $\mathrm{CH}_{2} \mathrm{O}$ (driven by the presence of dioxygen). The ligand 6 was isolated as two different $\mathrm{Co}^{\text {III }}$ complexes; cis- $[\mathrm{Co}(6+\mathrm{H})(\mathrm{en})]^{4-}$ and $t$ rans$[\mathrm{Co}(6+\mathrm{H}) \mathrm{Cl}]^{4+}$; the crystal structures of each complex cation are shown in Figures 2 and 3 respectively

In $c i s-[\mathrm{Co}(6)(\mathrm{en})]^{\text {at }}$ the ligand binds as a quadridentate. one primary amine is protonated while the aminal $N$-atom closer to the protonated amine is neither protonated nor



Figure 3. ORTEP view of the frams-[Co(6+H)Cl $\left.]_{2}\right]^{3+}$ cation. Selected bond lengths $(A)$ : $\mathrm{Co}-(1)-\mathrm{N}(1)$ 1.964(3), $\mathrm{Co}(1)-\mathrm{N}(2)$ $2.029(3), \mathrm{Co}(1)-\mathrm{N}(3) 1.966(3), \mathrm{Co}(1)-\mathrm{N}(4) 1.964(3), \mathrm{Co}(1)-\mathrm{Cl}(1)$ $2.245(1), \mathrm{Co}(1)-\mathrm{Cl}(2) 2.267(1)$. The intramolecular H-bond (Ni 3)$\left.\mathrm{H}^{\cdots} \mathrm{N}(5) 2.44 A, 116.1^{\circ}\right)$ is shown. coordinated. The chelating co-ligand ethane-1.2-diamine enforces a folded cis configuration of the quadridentate coordinated ligand. The primary and secondary amine $\mathrm{N}$ donors form $\mathrm{Co}-\mathrm{N}$ bonds of similar length but the bond to the coordinated tertiary amine $(\mathrm{N}(2))$ is much longer. as expected on the basis of steric effects. Although formally unprotonated. $\mathrm{N}(5)$ is engaged in a strong intramolecular $\mathrm{H}$ bond donated by the adjacent ethane-1.2-diamine ligand.

The trans-dichloro complex trans-[ $\left.\mathrm{Co}(6+\mathrm{H}) \mathrm{Cl}_{2}\right]^{+-}$was also isolated from the same synthesis. The geometry of the complex ion is shown in Figure 3. Again one primary amine is protonated and its adjacent tertiary amine remains unprotonated and also uncoordinated. A weak intramolecular $\mathrm{H}$ bond is present in this case from the secondary amine N(3) to the free tertiary amine. Again. the coordinated tertiary amine $(\mathbb{N}(2))$ forms the weakest bond of the four amine donors.

Optical Resolution of $[\mathrm{Co}(5)]^{3+}$. Chromatographic resolution of $[\mathrm{Co}(5)]^{3+}$ with the chiral antimony tartrate anion was readily achieved in a manner similar to that employed by us for related hexaanine $\mathrm{Co}^{111}$ complexes. ${ }^{-5}$ Separation is achieved by differential ion paring between the two enantiomers and the chiral anion: the stronger diasteromeric ion pair eluting more rapidly due to its diminished affinity for the cation exchange resin. The absolute configuration of the enantiomer more rapidly eluted by $\mathrm{Na}_{2}\left[\mathrm{Sb}_{2}(R . R \text {-tart })_{2}\right]$ was established as $\Lambda$ by $\mathrm{X}$-ray cry stallography. The coordination geometry: coordinate bond lengths and conformation detemined from the crystal structure of $\mathrm{L}-[\mathrm{Co}(5)]\left(\mathrm{ClO}_{4}\right) \mathrm{Cl}_{2}$ (Figure 5) match those of racemic $[\mathrm{Co}(5)] \mathrm{Cl}_{3} \cdot \mathrm{H}_{2} \mathrm{O}$.reported recently. ${ }^{18} \mathrm{As}$ in the racemate structure. $\mathrm{N}-\mathrm{H}{ }^{\cdots} \mathrm{Cl}(2.33-2.37$ A: $154-173^{\circ}$ ) and $\mathrm{N}-\mathrm{H}^{\cdots} \mathrm{O}$ H-bonding interactions are many, but it is notable that those involving the chloride ions fall in a particularly narrow range.

The acyclic $[\mathrm{Co}(5)]^{3+}$ complex is readily converted to the macrobicyclic cage compound $[\mathrm{Co}(3)]^{2-}$, a new member of



Figure 4. ORTEP view of $\mathrm{L}-[\mathrm{Co}(5)]^{3+}$ (30\% ellipsoids ). Selected bond lengths $(A)$ : $\operatorname{Co}(1)-\mathrm{N}(1) 1.973(2)$, Co(1)-N(2) 1.979(2), Co(1)-N(3) 1.969(2), Co(1)-N(4) $1.976(2) \operatorname{Co}(1)-N(5) 1.955(2)$. Co(l)-N(6) $1.971(2)$. 


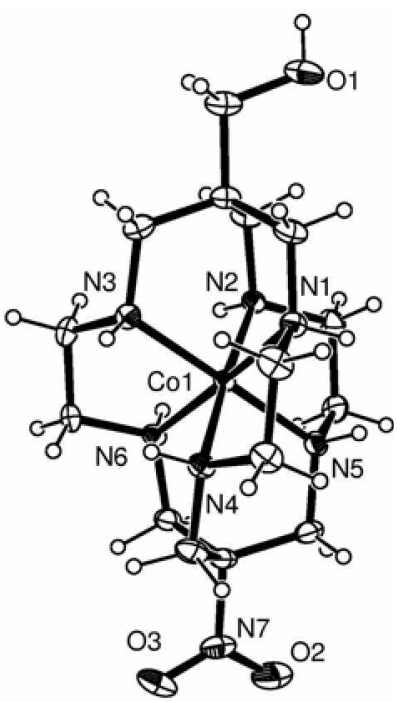

Figure 5. View of the racemic $[\mathrm{Co}(3)]^{3-}$ cation (30\% probability ellipsoids). Selected bond length $(\AA)$ : Co( 1$)-\mathrm{N}(1) 1.974(2)$, Co( 1 )$\mathrm{N}(2) 1.959(2), \mathrm{Co}(1) \mathrm{N}(3) 1.972(2), \mathrm{Co}(1)-\mathrm{N}(4) 1.976(2), \mathrm{Co}(1)$ $\mathrm{N}(5), 1.979(2), \mathrm{Co}(1)-\mathrm{N}(6) 1.975(2)$

the extended sarcophagine fanily, using well-established methods. ${ }^{1}$ The structure of the nitro-substituted cage complex $[\mathrm{Co}(3)] \mathrm{Cl}_{3} \cdot 1 \frac{1}{2} \mathrm{H}_{2} \mathrm{O}$ was determined. The nitro-cap is apparent in Figure 5. Structurally characterised $\mathrm{Co}^{\mathrm{III}}$ complexes from the sar family abound in the literature ${ }^{1.5 .50}$ and most exhibit the same $\mathrm{le} l_{3}$ conformation seen here (with the $-\mathrm{CH}_{z}-\mathrm{CH}_{z}$ groups of all five-membered chelate rings aligned with the 3 -fold axis of the complex

The $\mathrm{Co}-\mathrm{N}$ bond lengths in this conformation are similar to those of the acyclic parent $[\mathrm{Co}(5)]^{3-}$. All six secondary secondary amines participate in strong H-bonding interactions with the chloride ions $[\mathrm{H} \cdots \mathrm{Cl} 2.27-2.42 \AA, \mathrm{N}-\mathrm{H} \cdots \mathrm{Cl}$ $160-175^{\circ}$. as do the water and hydroxyl protons.

Optically pure $\Lambda-[\mathrm{Co}(3)]^{3-}$ was synthesised under identical synthetic conditions using the previously resolved precursor $\Lambda-[\mathrm{Co}(5)]^{3-}$. The absolute configuration of the cage complex was confirmed crystallographically from the mixed salt $\Lambda$ $[\mathrm{Co}(3)]\left(\mathrm{PF}_{6}\right) \mathrm{Cl}_{\mathrm{s}}$. The bond lengths and angles within the complex cation and its conformation do not differ significantly from those of the racemate. so no figure is shown of the structure. Once again all six secondary amines participate in strong $\mathrm{H}$-bonding interactions with chloride ions $[\mathrm{H} \cdots \mathrm{Cl}$ $2.17-2.33 \AA$. N-H $\left.{ }^{\cdots} \mathrm{Cl} 161-173^{\circ}\right]$, but not with the hexafluorophosphate anion. The hydroxyl proton of the ligand donates a weak hydrogen bond to a chloride ion $[O(1)$ $\left.\mathrm{H}(1 \mathrm{~A}){ }^{\cdots} \mathrm{Cl}(1)^{\prime} 2.66 \AA \mathrm{A}^{\circ}, 140^{\circ}\right]$.

Electronic Absorption and Circular Dichroism Spectroscopy. The electronic spectra of all complexes matched those of their sarcophagine analogues. Although the effective ligand fields are $C_{3}$ for $[C o(5)]^{3+}$ and $D_{3}$ for the cages only two broad $d-d$ maxinta were observed in the electronic


spectroscopy may reveal splitting of the first spin-allowed $d-d$ transition as the two component $\left({ }^{1} \mathrm{~A}_{2} \leftarrow{ }^{1} \mathrm{~A}_{1}\right.$ and ${ }^{1} \mathrm{E} \leftarrow$ ${ }^{1} \mathrm{~A}_{1}$ ) usually have opposite sign). ${ }^{3.5} \mathrm{CD}$ spectroscopy is also
Table 2. CD Maxima of Selected Hexaamine Co ${ }^{\text {III }}$ Complexes

\begin{tabular}{llc}
\hline Complex & \multicolumn{1}{c}{$\lambda_{\min m a x}[\mathrm{~mm}]\left(\Delta \varepsilon\left(\mathrm{M}^{-1} \mathrm{~cm}^{-1}\right)\right.$} & Reference \\
\hline$\Delta-[\operatorname{Co}(2)]^{3-}$ & $476(+2.68), 362(+0.17)$ & 24 \\
$\Delta-[\operatorname{Co}(2+2 \mathrm{H})]^{5+}$ & $491(+2.04), 353(+0.37)$ & 24 \\
$\Lambda-[\operatorname{Co}(3)]^{3-}$ & $473(-2.14), 343(-0.18)$ & This work \\
$\Delta-[\operatorname{Co}(4)]^{3-}$ & $467(-2.37), 362(-0.13)$ & This work \\
$\Delta-[\operatorname{Co}(5)]^{3+}$ & $488(+0.42), 440(-0.60), 340(+0.070)$ & 1 lhis work \\
\hline
\end{tabular}

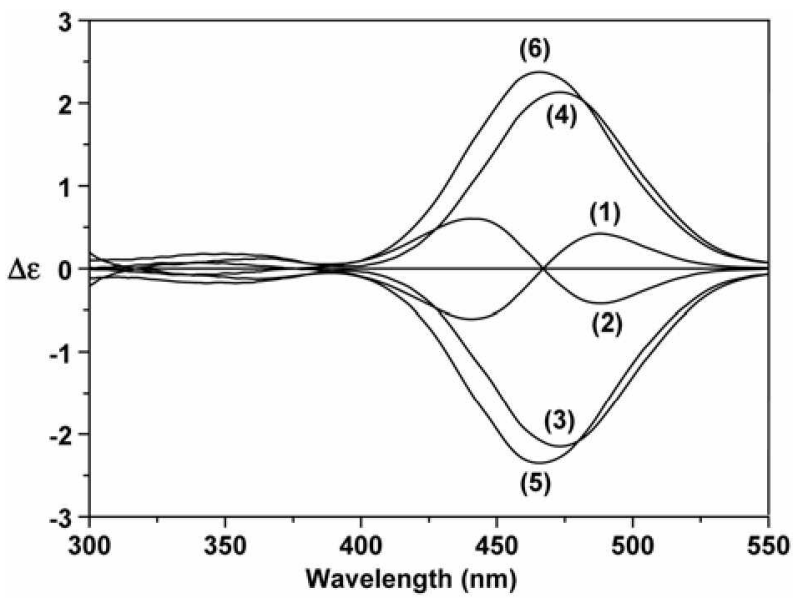

Figure 6. Circular dichroism spectra of (1) $\Lambda-[\operatorname{Co}(5)]^{3-},(2) \Delta-$ $[\mathrm{Co}(5)]^{3-}$, (3) $\Lambda-[\mathrm{Co}(3)]^{3+}$ (from complex $(1)$ j, (4) $\Delta-[\mathrm{Co}(3)]^{3-}$ (from complex (2)), (5) $\mathrm{A}-[\mathrm{Co}(4+\mathrm{H})]^{1+}$ (from complex (3)) and $(6)$ $\Delta-[\mathrm{Co}(4+\mathrm{H})]^{4-}$ (from complex $(4)$ ).

sensitive to the conformation of the five-membered chelate rings where conversions from the so-called $l e l$ ? to $w b_{3}$ conformation are accompanied by inversion of $\mathrm{CD}$ maxima. ${ }^{3}$ The solution spectra are compared in Figure 6 while the relevant data are assembled in Table 2 .

Firstly it is apparent that the CD spectra of the cage complexes $\Lambda-[\operatorname{Co}(3)]^{3+}$ and $\Lambda-[\operatorname{Co}(4)]^{3-}$ are essentially the same and mirror those of the diamino-substituted complex $\Delta-[\mathrm{Co}(2)]^{3-}$. By contrast the $\mathrm{CD}$ spectrum of the acyclic precursor $\Lambda-[\mathrm{Co}(5)]^{3+}$ is completely different. This complex lacks three chirotopic $\mathrm{N}$-donors found in the cage derivatives and this difference inverts the CD spectrum going from the acyclic complex to the cage (with the same absolute configuration at the metal centre). Also the effective symmetry of the ligand field is $C_{3}$ (as opposed to $L_{3}$ for the cages with six secondary amines). which will result in a different degree of



Electrochemistry. Cyclic voltammetry is reported for all complexes (except the dichlorotetraamine trans $-[\mathrm{Co}(6+\mathrm{H})$ $\left.\mathrm{Cl}_{1}\right]^{\text {t+ }}$ which was substitutionally labile upon reduction and led to complicated electrochemistry). All experiments were conducted on a static Hg drop working electrode. In each case the $\mathrm{Co}^{\text {III:III }}$ redox couple was of most interest and a reversible response was identified in each case. All roltanmograms measured at $\mathrm{pH} 6$ and at a sweep rate of $100 \mathrm{mV} \mathrm{s}^{-1}$ are shovin in Figure 7.

Some interesting features emerge from the data. Firstly, the mixed ligand complex $c i s$ - $[\mathrm{Co}(6+\mathrm{H})(\mathrm{en})]^{++}$exhibited the 




Figure 7. Cyclic voltammograms of acyclic and cage $\mathrm{CO}^{\mathrm{ll}}$ hexamines ( $2 \mathrm{~mm}$ solutions) showing $\mathrm{Co}{ }^{[\mathrm{Il}:] \mathrm{l}}$ redos couples only. Experimental conditions: $\mathrm{pH} 6$, sweep rate $100 \mathrm{mV} \mathrm{s}^{-1}$, static $\mathrm{Hg}$ drop working electrode, $0.1 \mathrm{~mol} \mathrm{~L}-1 \mathrm{NaNO}_{3}$ ).

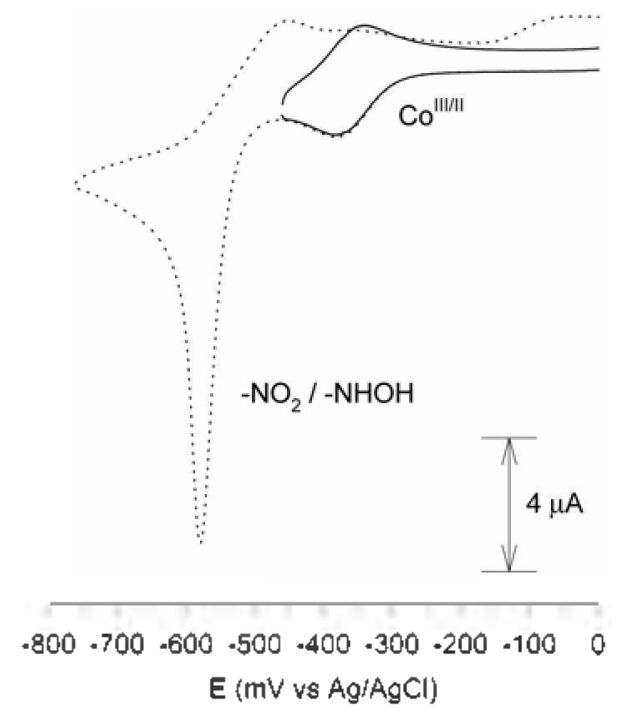

Figure 8. Cyclic voltanmograms of $[\operatorname{Co}(3)]^{3+}$ at two different reversal potentials. The extended sweep (broken curve) shows the multi-electron irreversible nitro group reduction. Experimental conditions the same as in Figure 7.

most positive redox couple $(-185 \mathrm{mV}$ \& $\mathrm{Ag} / \mathrm{AgCl}, \mathrm{pH} 6)$ which is likely to be a composite effect of the extra positive charge on the free protonated primary amine and the coordinated tertiary amine which both favour reduction to the divalent oxidation state. The electrochemistry of $[\mathrm{Co}(5)]^{3+}$ has been reported previously ${ }^{18}$ but the data are included here for comparison. The $\mathrm{Co}^{11 \mathrm{lili}}$ redox protential is $-517 \mathrm{mV}$ is $\mathrm{Ag} / \mathrm{AgCl}$. The electron withdrawing influence of the nitro group in $\left[\left.\mathrm{Co}(3)\right|^{3+}\right.$ is apparent in the anodically shifted $\mathrm{Co}{ }^{\text {IIIIII }}$ redox potential $(-360 \mathrm{mV}$ \& $\mathrm{Ag} / \mathrm{AgCl})$. Replacement of the nitro group with a primary amine in $[\mathrm{Co}(4)]^{\hat{j}-}$ lowers the redox potential to $-513 \mathrm{nl}$ is $\mathrm{Ag} / \mathrm{AgCl}$.



Figure 9. $\mathrm{pH}$-Dependent cyclic voltammetry of $[\mathrm{Co}(4)]^{3+}$ showing the formation of $[\mathrm{Co}(4+\mathrm{H})]^{3-}$ at low $\mathrm{pH}$ with an anodically shifted Co ${ }^{\mid 1]:[l}$ redox potential. Experimental conditions (except $\mathrm{pH}$ ) the same as in Figure 7.

The nitro group in $[\mathrm{Co}(3)]^{3-}$ is also electroactive. Continuing the sweep to low potential (Figure 8) reveals an irreversible multi-electron nitro group reduction and the reversibility of the Co response is lost. This feature has been discussed previously: ${ }^{27}$

The voltammetry of the amino-substituted analogue $\left[\left.\mathrm{Co}(\mathbf{4})\right|^{2-}\right.$ was $\mathrm{pH}$ dependent (Figure9). At $\mathrm{pH} 5$ and higher, the $\mathrm{Co}^{\text {Ill:11 }}$ couple is constant at $-513 \mathrm{mV}+\mathrm{sg} / \mathrm{AgCl}$ while at $\mathrm{pH} 3$ this couple shifts to at $-353 \mathrm{mV}$ vs $\mathrm{Ag} / \mathrm{AgCl}$. This may be explained by protonation of the $\mathrm{Co}^{\mathrm{II}}$ form at lower $\mathrm{pH}$ (t.e. $[\mathrm{Co}(4+\mathrm{H})]^{+-}$) which leads to an anodic shift in the $\mathrm{Co}(\mathrm{III} / \mathrm{ll})$ redox couple. At pH 4, two reversible responses are seen of approximately equal magnitude thus we can estimate the $\mathrm{pK}_{\mathrm{a}}$ of the pendent amine as around 4. More accurate determination of this protonation constant must await potentiometric titrations.

\section{Conclusions}

The $\mathrm{Co}^{\mathrm{III}}$ complexes of the new sarcophagine analogues $\mathbf{3}$ and 4 show closely similar spectral and electrochemical properties to those of simpler cage species. Given that the hydroxy substituent does not influence the bound metal characteristics. our hope is that the reverse also will apply: Thus. it should be possible to perform substitution reactions at the hydroxyl site without the deleterious steric and electronic effects that have hampered cage complex derivatisation reactions in the past. Here. we have also shown that the optically pure fonms of the $\mathrm{Co}^{\mathrm{III}}$ complexes of 3 and $\mathbf{4}$ are easily obtained, raising prospects for their use as chiral components of more elaborate systems. This work is currently under way. 
Acknowledgements. This work was supported by Korea Research Foundation Grant KRF-2004-015-C00247.

\section{References}

1. Geue. R. J.: Hambley. T. W.: Harrowfield. J. M.: Sargeson. A. M.: Snow. M. R. J Ant Chem. Soc. 1984. 106.5478.

2. Geue. R. J.: McCarthy. M. G.: Sargeson. A. M. J. Ant Chent. Soc. 1984. 106. 8282

3. Bernhardt. P. V: Bygott A. M. T: Geue, R. J: Hendry. A. J.: Korybut-Daszkiewicz, B. R.: Lay. P. A.: Pladziewicz. J. R.: Sargeson. A. M.: Willis. A. C. horg Ghem 1994 33. 4553.

4. Behm. C. A.: Boreham. P. F. L:: Creaser. I. I.: KorybutDaskiewicz. B.: Maddalena. D. J.: Sargeson. A. M.: Snowdon. G. M. Aust. J. Chent. 1995. 48.1009.

5. Moghaddas, S.: Hendry P.: Gelle. R. J.: Qin C: Brgott A. M. T: Sargeson. A. M.: Dixon. N. E. J. Chem. Soc. Dahtom Trans. 2000. 2085 .

6. Sargeson. A. M. Coord Chem. Rev: 1996. 151.89.

7. Di Bartolo. N. M.: Sargeson. A. M.: Donlevy. T. M.: Smith. S. V. J. Chent. Soc. Dahon Trans. 2001. 2303.

8. Walker. G. W. Gelle. R. J.: Sargeson, A. M: Behm. C. A. Dalton Trans. 2003. 2992.

9. Di Bartolo, N.: Sargeson, A. M.: Smith, S. V. Org. Bionol. Chem. 2006. 4.3350 .

10. Lay. P. A.: Maul. A.: Sasse. W. H. F.: Creaser. I. I.: Gahan. L. R.: Sargeson. A. M. Ihorg. Chem. 1983. 22.2347.

11. Creaser I. I. Gahan. L. R.: Geue, R. J: Launikonis, A.: Lay. P. A.: Lydon, J. D.: McCarthy, M. G.: Mau. A. W. H.: Sargeson A. M.: Sasse. W. H. F. horg. Chem. 1985. 24. 2671.
12. Koenigstein, C. Mau. A. W. H.: Osvath. P.: Sargeson, A. M. Chent Conmum 1997. 423.

13. Burnet. S.: Choi. M.-H.: Donnelly. P. S.: Harrowtield. T. M.: Ivanova. I.: Jeong. S.-H.: Kim. Y.: Mocerino. M.: Skelton. B. W: White, A. H; Williams, C. C.: Zeng. Z.-L. Ew . J horg. Chem. 2001. 1869

14. Donnelly, P. S: Harrowfield. J. M.: Skelton. B. W: White, A. H J. Chent. Soc. Dalton Trans. 2001. 3078.

15. Donnelly. P. S.: Harrowield. J. M.: Skelton. B. W.: White. A. H. Inorg. Chent 2000. 39. 5817.

16. Gajhede, M.; Hammershoi, A.: Skov. L. K. Acta Chem. Scand. $1991,+5,474$

17. Bernhardt, P. V.: Cho. J. H.; Harrowfield, J. M.: Kim, J. Y.; Kim. Y.: Sujandi: Thuery. P.: Yoon. D. C. Polyhedron 2006. 25. 1811.

18. Bernhardt. P. V: Kim. Y.: Sujandi Aust. J. Chent 2006. 59.783.

19. Gahan1. L. R.: Hambley. T. W.: Sargeson. A. M.: Snow. M. R. Inorg. Chem 1982, 21, 2699

20. Gahan. L. R.: Donlevy, T. M.: Hambley. T. W. Jnorg. Chem. 1990. 29. 1451 .

21. Farrugia. L. T. J. Appl Cnnt 1999.32.837.

22. Sheldrick. G. M. SHEL197, Prograns for Crustal Sintche Anahsis. University of Göttingen: Germany. 1997.

23. Farrugia, L. J. J. Appl. Coyst. 1997. 30, 565.

24. Harrowfield, J; Kim, J. Y.; Kim. Y.; Lee, Y. H.. Sujandi; Thuéry. P. Polvhedron $2005,24,968$.

25. Bernhardt. P. V.: Dyahningtyas. T. E.: Harrowfield. J. M.: Kim. T.Y.: Kinl. Y.: Rukmini. E. Alust. J. Chent 2003. 56. 1187.

26. Clark. I. J: Geue. R. I.: Engelhardt. L. M.: Harrowfield. J. M.: Sargeson, A. M; White, A. H. Aust. J. Chem. 1993. 46. 1485.

27. Bond. A. M.: Lawrance. G. A.; Lay. P. A.; Sargeson, A. M. Inorg. Chem $1983,22,2010$ 